\title{
ESPAÇOS NÃO EdIFICADOS NAS CONCESSÕES AGUDÁ: JARDIM ORNAMENTAL, POMAR E HORTA ${ }^{1}$
}

\author{
ALEXIS ADANDÉ
}

\begin{abstract}
RESUMO
Este artigo busca estabelecer uma comparação entre os jardins brasileiros e os jardins agudá, no Benin, África. Em seu movimento de retorno no fim do período escravagista brasileiro, ou ainda durante os séculos de escravidão, os africanos transportaram uma série de referências para o Benin, entre elas plantas presentes no cotidiano brasileiro, bem como concepções que orientaram a construção desses espaços (jardins ornamentais, pomares, hortas) em seu continente de origem. Destacando aspectos da diáspora africana no novo mundo, 0 texto apresenta algumas das trocas culturais estabelecidas entre o Brasil e partes do continente africano.
\end{abstract}

PALAVRAS CHAVE

Patrimônio imaterial; Agudá; Diáspora africana; Benin; Brasil.

\section{NON-EDIFIED SPACES IN CONCESSÕES AGUADÁ: ORNAMENTAL GARDEN, FRUIT RANCH AND VEGETABLE GARDEN}

\begin{abstract}
This article seeks to establish a comparison between the Brazilian gardens and the agudá gardens, in Benin, Africa. In their return movement at the end of the Brazilian slavery period, or even during centuries of slavery, Africans carried a series of references to Benin, among them the plants present in Brazilian daily life, as well as conceptions that guided the construction of these spaces (ornamental gardens, orchards, kitchen garden) in its continent of origin. Highlighting aspects of the African diaspora in the new world, the text presents some of the cultural exchanges established between Brazil and parts of the African continent.
\end{abstract}

\author{
KEYWORDS \\ Intangible heritage, aguda, African diaspora, Benin, Brazil. \\ ESPACIOS NO EDIFICADOS EN LAS CONCESIONES: AGUDÁ: JARDÍN ORNAMENTAL, \\ POMAR Y HUERTA
}

\begin{abstract}
RESUMEN
Este artículo busca establecer una comparación entre los jardines brasileños y los jardines agudá, en Benin, África. En su movimiento de retorno al final del período esclavista brasileño, 0 aún durante los siglos de esclavitud, los africanos transportaron una serie de referencias para Benín, entre ellas plantas presentes en el cotidiano brasileño, así como concepciones que orientaron la construcción de esos espacios (jardines ornamentales, pomares, huertas) en su continente de origen. Destacando aspectos de la diáspora africana en el nuevo mundo, el texto presenta algunos de los intercambios culturales establecidos entre Brasil y partes del

\footnotetext{
${ }^{1}$ Originalmente este artigo integra a obra coletiva Du Brésil au Bénin: contribution à l'étude despatrimoines familiaux aguda au Bénin, realizada sob a coordenação científica de Alexis Adandé, Lisa Earl Castillo, Didier Houénoudé, Luis Nicoalu Parès e Elisée Soumonni e publicado por Les Editions Plurielles, em março de 2018. A tradução do francês é de Rachel Rocha de Almeida Barros e a revisão é de Yann Hamonic.
} 
continente africano.

\author{
PALABRAS CLAVE
}

Patrimonio inmaterial, agudá, diáspora africana, Benin, Brasil.

\title{
LES ESPACES NON BÂTIS DANS LES CONCESSIONS AGUDA: JARDIN D'AGRÉMENT, VERGER ET POTAGER
}

\section{RÉSUMÉ}

Le présent article cherche à établir une comparaison entre les jardins brésiliens et les jardins agudá, au Bénin, en Afrique. À leur retour, à la fin de l'esclavage au Brésil, voire pendant les siècles d'esclavage, les migrants ont apporté une série de références au Bénin, parmi celles-ci des plantes présentes dans la vie quotidienne brésilienne, ainsi que des conceptions encadrant la construction d'espaces tels que les jardins ornementaux, les vergers ou les potagers, sur leur continent d'origine. En relevant des aspects de la diaspora africaine dans le nouveau monde, le texte montre certains des échanges culturels établis entre le Brésil et certaines parties du continent africain.

\section{MOTS-CLÉS}

Patrimoine immatériel; agudá; diaspora africaine; Benin; Brésil. 


\section{ESPAÇOS NÃO EDIFICADOS NAS CONCESSÕES AGUDÁ: JARDIM ORNAMENTAL, POMAR E HORTA}

Depois da caracterização do quadro material da vida doméstica interna, digamos assim, parece indispensável, ainda na esfera do privado, mencionar o denominado jardim agudá. De fato, ficamos surpreendido pela constância, nas concessões de tipo agudá (o modelo amplamente adotado até em meios que não são nem de ascendência, nem de cultura afro-brasileira, sobretudo nas cidades do sul do Benin), da presença de um jardim ornamental logo depois de cruzar o portão - antigamente monumental - e, se tiver a possibilidade, você irá visitar, no quintal, por trás da edificação central, o pomar, acompanhado da horta e do jardim das plantas medicinais. Trata-se da organização e do ordenamento dos espaços domésticos não edificados.

O estudo sistemático desses espaços ainda está para ser feito, pelo que sei. Entretanto, um de nossos estudantes de arqueologia começou a decodificação do pomar agudá (Azankpo, 2015). Esse estudo deu bons resultados sobre os quais vou me apoiar para evocar aspectos da cultura material frequentemente escondidos, o que dificulta a percepção da importância do impacto qualitativo da cultura do retorno nessa parte do continente africano (Salako, 2007).

Tratando-se de uma pesquisa em nível de mestrado, deveria ser feita em campo, a partir de alguns estudos de caso em Porto Novo, Sèmè-Kpodji e Ouidah, localidades nas quais o jovem pesquisador teve acesso a concessões agudá e à documentação vinculada. Dessas primeiras investigações, evidenciam-se algumas características comuns a todas as concessões agudá visitadas cujo mapeamento foi feito.

"A parte frontal do jardim ornamental que contém várias plantas ornamentais e flores mais ou menos perenes (exemplos: Acalypha hispida [rabo de raposa], Acalyphawilkesiana, Gardeniaimperialis [gardênia de flores brancas ou rosadas], Hibiscus rosa-sinensis [variedade de hibisco, rosa da China ou de Cayenne), Heliconiapsittacorum [bico de papagaio], Ixora coccínea (arbusto de flores vermelhas/cerca viva], Jasminumkerstingii [jasmim de Gana, Togo, Benin], Jasminiumdicotomum [jasmim dito de Gana], Jasminumofficianalis, Jasminumsambac (L) (jasmim originário da Índia), Lagerstroemiaindica (orgulho da India, flores cuja cor varia de rosa à roxo), Rosa eglanteria (roseira), Raystonearegia(palmeira real de Cuba)...]; O pomar e o quintal [exemplos: Aloes vera, Catharanthusroseus (vinca de Madagascar), Ocimumgratissimum (manjericão da folha grande, tchamadido), Newbouldialaevis (hisopoafricano), Calotropisprocera (maçã de Sodome), Lawsoniainermis (hena, lalitin), Caricapapaya (mamoeiro), Cymbopogoncitratus (citronela), Zingiberofficinale (gengibre) para o quintal e, no caso da horta, Capsicumannuum (pimenta), Capsicumfrutenscens (variedade de pimenta), Vernoniaamygdalina2 (alumã), Hydrocotylebonariensis (centenária) [...."

"O pomar, geralmente no quintal, onde pode se encontrar um galinheiro, uma criação de coelhos, ou até mesmo um aprisco ou uma pocilga, e a garagem (exemplo de

\footnotetext{
${ }^{2}$ Nota do revisor: chamado vassourão no Nordeste ou Ewurô pela cultura Jêje-Nagô.
} 
algumas árvores frutíferas: Magniferaindica (mangueira), Theobromacacao (cacauzeiro), Annonasquamosa (pé de canela), Tamarindos indica (tamarineiro), Ziziphusmauritiana (jujuba), Anacardiumoccidentale (cajueiro), Ananascomosus (abacaxi), Annonamuricata (noz moscada), Artocarpusaltilisou comunis (fruta pão), Persea americana (abacateiro), Psidiumguyava (goiabeira), Citrussinensis (laranjeira doce), Citruslimon (limoeiro, limão), Citrusaurentifolia (lima comum), Citrusreticulata (tangerina), Citrusmaxima (pomelo), Cocos nucifera (coqueiro), Musa acuminata (banana-da-terra), Musa paradisíaca (banana figo), Elaeis guineenses (dendezeiro), Manilkarazapota(sapotizeiro), etc. (cf. Akoègninou et al., 2006). Vale lembrar aqui a preocupação de alguns participantes do ateliê em Agouè, diante do que thes parecia uma tendência ao desaparecimento de algumas frutíferas, antes familiares em sua própria paisagem, como a pitanga (cerejeira do Brasil ou de Cayenne): Eugenia uniflora, ou ainda do coração de boi ou cachiman (Annonareticulata) citados como exemplos".

A fim de valorizar globalmente o patrimônio imobiliário agudá, será necessário lembrarmo-nos que na tipologia dos sites, segundo o Centro do Patrimônio Mundial da UNESCO, essa herança da "era atlântica", tomada em seu conjunto, integra a categoria das paisagens culturais e, precisamente, das paisagens criadas pelo homem (jardins e parques paisagísticos, por razões estéticas, associados, às vezes, a religiões e aos conjuntos monumentais). Poderia igualmente se associar à categoria paisagens evolutivas vivas e ser catalogada junto com os patrimônios tangíveis afro-brasileiros em países fronteiriços, e constituir um itinerário cultural e uma rota de trocas que, por causa da sua singularidade, seria a rota dos retornados ou "a rota do retorno dos Afro-Brasileiros", o complemento natural da Rota do Escravo. Um importante ponto de reflexão e de ação para nossos gestores do patrimônio (Varissou, 2001, p. 9).

Da mesma forma, tratando-se de pesquisas holísticas relativas à transferência e à aclimatação de essências exóticas nessa parte do golfo da Guiné, será preciso ser muito atento para diferenciar entre as plantas introduzidas pelos jardins de orientação europeia por um lado e, por outro, os de aclimatação colonial, também de sementes trazidas tanto por funcionários quanto pela infantaria daomeana de volta pra casa após seu serviço no exército francês em diversas partes das federações da África Ocidental Francesa e da África Equatorial Francesa ou de outros lugares. Embora os agudá tenham constituído boa parte desses contingentes, eles não eram os únicos, e esse costume de trazer ao país espécies interessantes era bastante comum entre os daomeanos.

Um outro interesse dessa verdadeira introdução a uma história da horticultura na Costa oriental do golfo da Guiné (fora dos fortes europeus, cf. Juhé-Beaulaton, 1994) é que ela nos coloca em contato direto com o continente de origem da maior parte das árvores frutíferas domesticadas pelos indígenas do continente americano, colocando igualmente com precisão a questão das relações dos afro-brasileiros e, mais geralmente, dos africanos com as flores ornamentais; dito de outra maneira, a origem ou as origens da floricultura na região da Costa oriental do golfo da Guiné. De onde provinham todas essas flores, todas essas plantas ornamentais? Em seguida agora uma questão relativa ao imaterial: existiria uma 
arte de confeccionar buquês entre as mulheres agudá? Se sim, como foi transmitida? (admito o aspecto subjetivo dessa questão orientada; de fato, por que não entre os homens? Nos mercados das cidades, nos jardins e à beira das vias urbanas no Benim e no Togo de hoje, os floristas são sobretudo homens). Existe aí um campo de investigação vasto e necessariamente pluridisciplinar, até mesmo verdadeiramente interdisciplinar; aos botânicos e palinólogos ${ }^{3}$, aos arqueobotânicos, devem ser associados arqueólogos, historiadores da arte, paisagistas e, naturalmente, horticultores. O Brasil é também reputado pela inventividade de seus criadores de jardins e de seus paisagistas. Uma razão a mais para nutrir com esse meio laços estreitos de cooperação científica e de trocas culturais.

\section{REFERÊNCIAS:}

AKOÈGNInOU, A. et al. Flore Analytique du Bénin. Cotonou/Wageningen: Backhuys Publishers, 2006.

AZANKPO, R. Le verger aguda dans le Sud-Bénin (XIXe-XXe s.): apports au patrimoine végétal et impactis sur les habitu des alimentaires. In: Mémoire de Maîtrise en Archéologie. Universitéd'Abomey-Calavi, 2015.

JUHÉ-BEAULATON, Dominique. Les jardins des forts européens de Ouidah: premières jardins d'essai (XVIII esiècle). In: Spécial Togo-Bénin-Cahiersdu Centre de RecherchesAfricaines (CRA). Paris: Karthala, 1994, p. 83-105.

SALAKO, 0. G. P. Impact de la traite des esclaves transatlantique sur le paysage végétal du Sud-Bénin. In: Mémoire de Maîtrised'Histoire. Universitéd'Abomey-Calavi, 2007.

VARISSOU, Souayibou. Porto-Novo et ses Environs - Guide des paysages culturels. PortoNovo: Les éditions de l'EPA, 2001.

Recebido em 30 de julho de 2018.

Aprovado em 06 de dezembro de 2018.

\footnotetext{
${ }^{3}$ Nota do revisor: a palinologia é uma parte da botânica.
} 